\title{
Under nutrition and Associated factors among infants and young children age 6-23 months attending Minilik II Hospital, Ethiopia, 2021.
}

Lelisa Worku ( $\square$ lalisaworku@gmail.com )

Rift Valley University

Desta Assefie

Rift Valley University

Dube Jara

Rift Valley University

Addisu Tadesse

\section{Research Article}

Keywords: Undernutrition, stunting, wasting, underweight, 6-23 months

Posted Date: August 18th, 2021

DOI: https://doi.org/10.21203/rs.3.rs-820456/v1

License: (1) This work is licensed under a Creative Commons Attribution 4.0 International License. Read Full License 


\section{Abstract}

Globally, 47 million children young age were wasted, 14.3 million are severely wasted and 144 million are stunted. Around $45 \%$ of deaths among children are linked to undernutrition. The impact undernutrition is more severe among children age 6-23 months as this period is critical for child development, and irreversible damages can occur due to nutritional deficiencies. Hence aimed to assess magnitude of under nutrition and associated factors among infants and young children age 6-23 months attending Minilik II hospital, Addis Ababa, Ethiopia. Hospital based cross-sectional study was conducted among 377 Infant and young children age 6-23 months were selected using simple random sampling method. Data was collected using face-to-face interview with family and anthropometric measurement was taken. The anthropometric measurements of children were evaluated using WHO standard Antro software.

Descriptive statistics was used to describe the characteristics of study population. Logistic regression was fitted to identify factors associated with under nutrition. The study revealed about $34.1 \%$ of young age children were under nutrition while $28.8 \%$ of them stunted, underweight $10.2 \%$ and $4.7 \%$ of them were wasted. Working condition of mother (AOR $=6.142,95 \% \mathrm{Cl}: 2.90-13.01)$, education status of the mother $(\mathrm{AOR}=5.75,95 \% \mathrm{Cl}: 2.621-12.624)$, household live in rent house (AOR = 3.03, 95\% Cl: $1.30-7.04)$, illness/disease (AOR = 5.69, 95\% Cl: 2.360-13.623), inappropriate complementary feeding (AOR = 3.10, $95 \% \mathrm{Cl}: 1.37-7.04)$, breast feeding, receiving vitamin $\mathrm{A}(\mathrm{AOR}=0.17,95 \% \mathrm{Cl}: 0.08-0.34)$ and growth monitoring $(A O R=0.288$ at $95 \% \mathrm{Cl}(0.14-0.58)$ were found to have statistically significant association with children under nutrition.

\section{Introduction}

Undernutrition continues to affect the lives of millions of children and women worldwide and every country is affected by some form of nutrition problem(1). Globally, 47 million children young age were wasted, 14.3 million are severely wasted and 144 million are stunted and mostly occur in low- and middleincome countries(2).

About half of all stunted children lived in Asia and over one third in Africa and approximately two thirds of all wasted children lived in Asia and almost one third in Africa, with similar proportions for severely wasted children(3). At least one in three children is not getting the nutrition they need to grow well, particularly in the crucial first 1,000 days - from conception to the child's second birthday - and often beyond(4).

Young age children undernutrition continues to be the leading public health problem in developing countries(5). Africa has experienced the smallest relative decrease, with underweight from $23-17 \%$. This means Africa was likely fall meet the MDG, reaching about only half of the targeted reduction(3). Africa has one of the highest levels of child undernutrition, Stunting was highest in Burundi (57.7\%) and Malawi $(47.1 \%)$ in East Africa; Niger (43.9\%), in West Africa; Democratic Republic of Congo (42.7\%), Chad (39.9\%) in Central Africa and Ethiopia (8.70\%) in East Africa (6). 
In Ethiopia, from the year 2005 to 2016, there is a decrease in stunting from 47-39\%, but the prevalence of wasting changed little over the same time period (11-10\%)(7). Undernutrition among young children was one of the public health problems in Ethiopia. The prevalence of stunting, wasting, and underweight were $38.3 \%, 10.1 \%$, and $23.3 \%$, respectively (8). About $19.47 \%$ of children were both stunted and underweighted, and only $3.87 \%$ of children had all the three conditions(8).

In Addis Ababa, the prevalence of malnutrition and classifies it according its degree which is $55.1 \%, 57.7 \%$ and $49.26 \%$ measured with weight for age, weight for height and mid upper arm circumference respectively $(9)$.

Poor nutrition in the first 1,000 days of a child's life can lead to stunted growth, which is irreversible and associated with impaired cognitive ability and reduced school and work performance(10). Under nutrition may be a consequence of energy deficit or micronutrient deficiency. It is considered the most relevant risk factor for illness and death, particularly in developing countries like Ethiopia(11).

Inadequate nutrition during the first two years of life may lead to childhood morbidity and mortality, as well as inadequate brain development(12).

Infants and children undernutrition remains one of the major public health problems in many parts of the world, especially in a developing country, in which young age children are more vulnerable group to undernutrition (13).

The developmental, economic, social, and medical impacts of the global burden of undernutrition are serious and lasting, for individuals and their families, for communities and for countries(2). As recent report indicates Around $45 \%$ of deaths among children young age are linked to undernutrition(2). Similarly, In Ethiopia, undernutrition is a leading cause of child illness and death(5).

According to 2018 global nutritional report undernutrition was major bottlenecks for economic development(14). The study on economic impact of disease-related undernutrition at hospital admission determinants of cost deviation shows that the cost of treating a nutritionally-at-risk patient is $20 \%$ higher than the average of the respectively(15).

The hospital staying of undernourished young age children is long when compared with well-nourished. But also, incidence of complication and high-cost hospitality that has an impact directly or indirect on economy and other crisis on the family(16).

Undernutrition puts children at greater risk of dying from common infections, increases the frequency and severity of such infections, and contributes to delayed recovery due to potentially decrease immunity(1011). Additionally, the interaction between undernutrition and infection can create a potentially lethal cycle of worsening illness and deteriorating nutritional status(10).

Inappropriate complementary feeding practices among children aged 6-23 months is major cause of under nutrition(17). Breast feeding, sociodemographic condition, hygiene of food are also most 
associated factors with undernutrition of young age group children(18).

The impact undernutrition is more severe among children age 6-23 months as this period is critical for child development, and irreversible damages can occur due to nutritional deficiencies(19). For instance, undernutrition lacking brain development that lead to lack of attention (poor attention span), reducing academical performance and lowering the IQ level of the children(20). Generally, undernutrition can reduce physical (growth), mental and social development of young age children(21).

The consequence of the problems can affect the children, the family and the development of the country by lowering growth domestic product, economic level, complicating health service when aggregated and complicated.

\section{Methods And Materials}

\subsection{Study area and period}

This study was conduct at Minilik II hospital from May 1/2021 to June 25/2021. Minilik II hospital referral hospital is found in Addis Ababa city Yeka Sub city near kebena. The hospital start works during 1902 by few health workers. Now day the hospital manipulated by more than 950 health workers and 480 supportive staff for giving different service. Menelik II hospital was the first hospital started eye bank in Ethiopian history. Currently, hospital give different services by inpatient and outpatient including child health service. Under catchment of the hospital 969 under two years held as a plan in this year (2013 E.C). At hospital under child health service growth monitoring and screening nutritional status service are the major nutritional concern service.

\subsection{Study design}

Hospital based cross sectional study was conducted through quantitative approach.

\subsection{Population}

\subsubsection{Source of population}

All infants and young children age 6-23 months who come to hospital for different services.

\subsubsection{Study population}

All Infant and young children 6-23 months whose fitted inclusion criteria but not excluded by exclusion criteria.

\subsubsection{Eligibility criteria}

\subsubsection{Inclusion criteria}

- Infants and children between 6-23 months those come to hospital during data collection period. 


\subsubsection{Exclusive criteria}

- Children or infants or mothers/caregiver who were critically sick and in life threaten situation and unable to talk or hear.

- Children having physical disabilities that can interfere the anthropometric measurement.

- The infants or children who known as undernutrition and held in treatment of clinical nutrition to avoid exaggeration of result.

\subsection{Sample size determination}

The sample size $(n)$ required for the study was calculated using the formula to estimate a single population proportion by considering the following assumptions.

$\mathrm{Za} / 2=$ critical value for normal distribution at $95 \% \mathrm{Cl}$ to 1.96 ( $\mathrm{Z}$ value at alpha $=0.05)$. According to the study conducted in 2019 at Tigray region was about $33.7 \%, 15.7 \%$ and $4.8 \%$ of young children were stunting, underweight and wasting respectively(22).

a) Hence, according to the study; $P=33.7 \%$ for stunting:

$d(w)=$ margin of error of 0.05 with $95 \%$ Cl level.

$\mathrm{n}=(\underline{\mathrm{Za} / 2})^{2} \mathrm{P}(\underline{1-p})$.

$d^{2}$

$\mathrm{n}=(\underline{1.96}) \underline{{ }^{2} 0.337}(\underline{1-0.337})$.

$(0.05)^{2}$

$n=343+10 \%$ non-response

$n=377$

b) According to study conducted in Tigray region (2019),

$P=(15.7 \%)$ for underweight

$d(w)=$ margin of error of 0.05 with $95 \%$ Cl level.

$\mathrm{n}=(\underline{\mathrm{Za} / 2})^{2} \mathrm{P}(\underline{1-p})$. 
$\mathrm{n}=(\underline{1.96})^{20.157}(\underline{1-0.157})$.

$(0.05)^{2}$

$n=238+10 \%$ non-response

$n=262$

c) According to study conducted in Tigray region (2019),

$P=(4.8 \%)$ for Wasting

$d(w)=$ margin of error of 0.05 with $95 \%$ Cl level.

$n=(\underline{Z a / 2}) \underline{{ }^{2} P}(\underline{1-p})$.

$d^{2}$

$\mathrm{n}=(\underline{1.96})^{20} 0.048(\underline{1-0.048})$.

$(0.05)^{2}$

$n=70+10 \%$ non-response

$\underline{n=77}$

Sample size calculation for associated factors

The sample was calculated by double population proportion through online web (www.openinfo.com) by considering power $(1-\beta)$ that is $80 \%$, significance level $(\mathrm{Za} / 2)$ that is 0.05 since $95 \% \mathrm{Cl}$, allocation ration (exposed to unexposed) that is equal ration 1:1 was taken and effect size(proportion) was taken from community based cross-sectional study conducted in Ethiopia near Dabata (23). Finally, the obtained sample and odd ration was presented in Table 1. 
Table 1

Sample size calculated for associated factors, Undernutrition and associated factors among young age children 6-23 months, Addis Ababa, Ethiopia, 2021

\begin{tabular}{|llllllll|}
\hline $\begin{array}{l}\text { S. } \\
\text { no }\end{array}$ & Factors & $\begin{array}{l}\text { Power } \\
(1-\beta)\end{array}$ & $\begin{array}{l}\text { P-among } \\
\text { unexposed }\end{array}$ & $\begin{array}{l}\text { p-among } \\
\text { exposed }\end{array}$ & Ratio & OR & $\begin{array}{l}\text { Sample size with } \\
10 \% \text { non-response }\end{array}$ \\
\hline 1 & $\begin{array}{l}\text { Uneducated } \\
\text { mother }\end{array}$ & $80 \%$ & 0.609 & 0.391 & 1 & 13.9 & 200 \\
\hline 2 & $\begin{array}{l}\text { Uneducated } \\
\text { father }\end{array}$ & $80 \%$ & 0.602 & 0.398 & 1 & 4.7 & 227 \\
\hline 3 & Low income & $80 \%$ & 0.681 & 0.319 & 1 & 4.6 & 77 \\
\hline 4 & Age (12-23) & $80 \%$ & 0.67 & 0.33 & 1 & 0.28 & 84 \\
\hline 5 & No diarrhea & $80 \%$ & 0.144 & 0.856 & 1 & 0.37 & 22 \\
\hline 6 & Diarrhea & $80 \%$ & 0.2517 & 0.7483 & 1 & 3.16 & 42 \\
\hline 7 & Fever & $80 \%$ & 0.2067 & 0.8933 & 1 & 2.08 & 22 \\
\hline
\end{tabular}

Therefore, our largest sample was the sample size calculated for stunting it was 377 .

\subsection{Sampling Technique}

The sample was collected for 25 days, more than 30 under two years come to hospital every day. To cover 377 sample within 25 days, more than 15 children were selected from expected department. So, half of children were included every day by lottery method. There three departments to expected to serve the children, immunization departments serve more than 50 children means more than 8 children per day. Among those 8 children 4 children were selected by lottery method (rolled paper coded with 0 (off) and 1 (on)). Likewise, 8 children per day from 16 children come to medical ward/OPD and three children per day from 6 children of surgical ward. Finally, two children were added from immunization departments after the end of the day (26th day). See Fig. 1.

\subsection{Variable}

\subsubsection{Dependent variable}

- Undernutrition

\subsubsection{Independent variables}


Sociodemographic factors

- Age

- Sex

- Educational status of mother,

- Employment condition of mother

- Family income

- house condition (rent/own)

Maternal and child health service

- Immunization of children

- Vitamin A supplementation for children

- Growth monitoring program

- Birth order

- Birth interval

- Diarrhea

- Acute respiratory disease

- Measles

- Fever

Feeding practice

- Breast feeding

- Complementary feeding

- Frequency of feeding

- Feeding amount

- Method of feeding

Food safety hygiene

- Hand washing

- Duration of food after prepared

- Using soap for hand washing

\subsection{Operational definition}




\section{Minimum dietary diversity}

The proportion of children aged 6-23 months who received 4 or more food items among the seven food groups(24).

\section{Diarrhea}

Children with a history of $\geq 3$ times loose stool or watery diarrhea per day for two weeks prior to the study(24).

\section{Stunting}

Length for age $<-2$ SD of the WHO growth standard(24).

\section{Underweight}

Weight for age less than - 2SD of the WHO growth standard(24).

\section{Wasting}

Weight for length $<-2$ SD of the WHO growth standard(24).

\section{Under nutrition}

According to this study, any children recording one or more measurement indices less than - 2SD of Length for age, weight for age or weight for length against WHO growth standard is considered as undernutrition.

\subsection{Data collection tools and methods}

Data were collected using structured questionnaire that adapted from FAO (2016) for socio-demographic and nutritional related data.

Data were collected by trained data collectors through face-to-face interview with family or care giver of candidate infants and young children. The length of a child was measured using a horizontal wooden length board in recumbent position, and read to the nearest $0.1 \mathrm{~cm}$. Child weight was measured to the nearest $0.1 \mathrm{~kg}$ by beam balance. Weight was taken with light clothing and no shoes. Instrument calibration was done before weighing each child. Furthermore, the weighing scale was checked daily against the standard weight for accuracy. To check edema, normal thumb pressure was applied on both feet for three seconds. The data collectors were check whether a shallow print was remained on both feet or not when the thumb was lifted. To estimate nutritionally status anthropometric measurement used after individually calculated $z$ score of indices by WHO Anthro software version 3.2.2.

\subsection{Data Quality control}


To ensure quality of data questionnaire was translated to local language (Amharic) and back translated to English for consistency by expertise for clarity. Training was given for data collectors and supervisors on the purpose of the study, methods of data collection, how to take anthropometric measurements and ensure ethical issues. Overall work of data collection procedures and process was followed by investigator. Pre-test was done on $5 \%$ sample out of the study area. Necessary correction was made based on the result of pretest data analysis. Data were checked and then filled in to epidata software since the software has pre-set rule to reduce error.

\subsection{Data processing and analysis}

Data were checked for completeness and consistencies and then it was cleaned, coded, and entered using Epidata 3.1 and exported to the Statistical Package for Social Science (SPSS) software version 25 for analysis. Descriptive statistics were used to describe the study population about relevant variables. Logistic regression was fitted to identify the association between dependent (under nutrition) and independent variables. The analysis was conducted to select candidate variables to the initial multivariable model. Those variables that show association with under nutrition at a p-value less than 0.2 was included in an initial multivariable logistic regression model. Both crude and adjusted odds ratios with their corresponding $95 \%$ confidence interval was used to determine the strength of association. Assumptions of logistic regression was checked before final multivariable analysis using probability Bivariable graph and collinearity diagnostic (Variance inflation factor and correlation matrix). The final multivariable model goodness of fit was checked using classification table percentage, Hosmer-and Lemeshow chi-square test, and log-likelihood chi-square test. A p-value of less than 0.5 was used to declare the statistical significance of the finding in this study. The result was presented using text, tables, and graphs based on the types of data.

\section{Result}

\subsection{Sociodemographic and socio-economic characteristics of infants and young children}

Three hundred sixty-one 361 (95.7\%) of children/mothers were participated in this study, out of them $232(64.7 \%)$ of children were belong to age group 12-23 months and $197(54.6 \%)$ were male. Regarding to occupation of and education of mother, $188(51 \%)$ of mothers were employed either in the government and private institution, and 206(57.1\%) had no formal education (Table 2). 
Table 2

Socio-demographic and socio-economic characteristics of infants and young children age 6-23 months attending Minilik II Hospital, Ethiopia, 2021.

\begin{tabular}{|c|c|c|c|}
\hline Variable & Alternatives & Frequency & Percent \\
\hline \multirow[t]{2}{*}{ Age } & $6-11$ & 129 & 35.7 \\
\hline & $12-23$ & 232 & 64.3 \\
\hline \multirow[t]{2}{*}{ Sex } & Male & 197 & 54.6 \\
\hline & Female & 164 & 45.4 \\
\hline \multirow[t]{2}{*}{ Maternal education status } & No formal education & 206 & 57.1 \\
\hline & Educated & 155 & 42.9 \\
\hline \multirow[t]{2}{*}{ Occupation of Mother } & Employed & 184 & 51 \\
\hline & House wife & 177 & 49 \\
\hline \multirow[t]{2}{*}{ House condition (rent) } & Yes & 221 & 61.2 \\
\hline & No & 140 & 38.8 \\
\hline \multirow[t]{2}{*}{ Monthly income } & Less 5000 ETB & 83 & 30.7 \\
\hline & 5000ETB or more & 187 & 89.3 \\
\hline
\end{tabular}

\subsection{Feeding practice of mothers/caregiver of infants and young children}

Of the total, $292(80.9 \%)$ of the mothers were currently feeding breast their children and $296(82 \%)$ of mother used bottle feeding. $280(77.6 \%)$ of mothers feed their child by appropriate frequency, feeding amount $279(77.3 \%)$ and $174(48.2 \%)$ of mothers feeding appropriate type of food with respect to their age. $199(55.1 \%)$ of children were not feed appropriate complementary feeding. 251 (69 children were feed by their mothers or caregiver and only $6(1.7 \%)$ of children were feed by their fathers. $266(59.8 \%)$ of children were received vitamin A supplements during past six months (Table 3). 
Table 3

Feeding practice of mother/caregiver of infants and young children age 6-23 months attending Minilik II Hospital, Ethiopia, 2021.

\begin{tabular}{|c|c|c|c|}
\hline Variables & Alternatives & Frequency & Percent \\
\hline \multirow[t]{2}{*}{ Currently on breast feeding } & Yes & 292 & 80.9 \\
\hline & No & 69 & 19.1 \\
\hline \multirow[t]{2}{*}{ Bottle feeding } & Yes & 296 & 82 \\
\hline & No & 65 & 18 \\
\hline \multirow[t]{2}{*}{ Meal frequency } & Appropriate & 280 & 77.6 \\
\hline & Not appropriate & 81 & 22.4 \\
\hline \multirow[t]{2}{*}{ Amount of feeding } & Appropriate & 279 & 77.3 \\
\hline & Not appropriate & 82 & 22.7 \\
\hline \multirow[t]{2}{*}{ Snack feeding } & Yes & 250 & 84.2 \\
\hline & No & 87 & 25.8 \\
\hline \multirow[t]{3}{*}{ Who feeding child } & Mother & 251 & 69.5 \\
\hline & Caregiver & 104 & 28.8 \\
\hline & Father & 6 & 1.7 \\
\hline \multirow[t]{2}{*}{ Type of foods } & Appropriate & 174 & 48.2 \\
\hline & Not appropriate & 187 & 51.8 \\
\hline \multirow[t]{2}{*}{ Appropriate complementary feeding } & Appropriate & 162 & 44.9 \\
\hline & Not appropriate & 199 & 55.1 \\
\hline \multirow[t]{2}{*}{ Received Vitamin A } & Yes & 216 & 59.8 \\
\hline & No & 145 & 40.2 \\
\hline
\end{tabular}

\subsection{Food hygiene and safety practice of mother/caregiver}

Based on self-report of mothers/caregiver of children, 361(100\%) all mother/caregiver wash their hand before give meal for child but only $181(50.1 \%)$ of them wash their hand by soap. 336(93.1\%) mother/caregiver give fresh and home prepared food for their child (Table 4). 
Table 4

Food hygiene and safety practice of mother/caregiver of infants and young children age 6-23 months attending Minilik II Hospital, Ethiopia, 2021.

\begin{tabular}{|lllll|}
\hline Variables & Alternatives & Frequency & percent \\
\hline Fresh and home prepared food & yes & 336 & 93.1 \\
\cline { 2 - 5 } & No & 25 & 6.9 \\
\hline Hand washing before meal & yes & 361 & 100 \\
\hline Using soap for hand washing & yes & 0 & 0 \\
\hline Overall hygiene status & No & 181 & 50.1 \\
\hline
\end{tabular}

\subsection{Maternal and child health service}

Seventy-three (20\%) children were currently sick by different disease $36(49.3 \%)$ by diarrhea and $20(27.4 \%)$ by cough. 30(10\%) of children had history of recently sick and treated in health facilities. None of mothers were sick by psychiatric disorder. Most of children (216) (59.8\%) were received vitamin A during past six months and more than half of children (201) (55.7\%) were held under growth monitoring program for monitored their nutritional status. $318(88.1 \%)$ of young age children were vaccinated with respect to their age (Table 5). 
Table 5

Maternal and child health service of infants and young children age 6-23 months attending Minilik II Hospital, Ethiopia, 2021.

\begin{tabular}{|c|c|c|c|}
\hline Variables & Alternatives & Frequency & Percent \\
\hline \multirow[t]{2}{*}{ Currently sick children } & yes & 73 & 20.2 \\
\hline & No & 288 & 79.8 \\
\hline \multirow[t]{4}{*}{ Disease } & Diarrhea & 36 & 49.3 \\
\hline & cough & 20 & 27.4 \\
\hline & fever & 13 & 17.8 \\
\hline & other & 4 & 5.5 \\
\hline \multirow[t]{2}{*}{ Recently sick } & yes & 30 & 10.3 \\
\hline & No & 261 & 89.7 \\
\hline \multirow[t]{2}{*}{ Receiving vitamin, A past six months } & Yes & 216 & 59.8 \\
\hline & No & 145 & 40.2 \\
\hline \multirow[t]{2}{*}{ Children in Growth monitoring program } & yes & 201 & 55.7 \\
\hline & no & 160 & 44.3 \\
\hline \multirow[t]{3}{*}{ Vaccinated with schedule } & Never vaccinated & 14 & 3.9 \\
\hline & Vaccinated & 318 & 88.1 \\
\hline & Vaccinated but not in schedule & 29 & 8 \\
\hline
\end{tabular}

\subsection{Magnitude of Under nutrition among infants and young children}

One hundred twenty-three (34.1\%) $(29.2-39.2 \%$ at $95 \% \mathrm{Cl})$ of children were undernutrition among them one hundred four $(28.8 \%)(24.2-33.8 \%$ at $95 \% \mathrm{Cl})$ of them stunt, thirty-seven $(10.2 \%)(7.3-13.9 \%)$ of them underweight and seventeen (4.7\%) $(2.4-7.4 \%$ at $95 \mathrm{Cl})$ of them were wasting (Fig. 2).

\subsection{Factors associated with under nutrition among infant and young children}

Bivariable logistic regression was conducted to select candidate variables with $P$ value less than 0.2 . In Bivariable analysis working condition of mother, educational status of mother, living in rent house, bottle feeding, appropriate meal frequency, appropriate feeding amount, Food variety, appropriate complementary, Receiving Vitamin, a Growth monitoring, currently on breast feeding and Sickness were associated with outcome variable at $P$ value less than 0.2 . Accordingly, all the twelve variables were 
included in the initial multivariable logistic regression model, which eight of the were found to have independent and statistically significant association with dependent variable at $5 \%$ level of significance.

The working condition of the mothers was found to be statistically significant with child undernutrition, in which children of employed mothers were six times more likely to develop under nutrition as compared with children of unemployed mothers [AOR $=6.142(2.900-13.010)]$. The children of mothers who had no formal education were 5.7 times more likely to develop undernutrition as compared with children of mothers who had formal education [AOR $=5.752(2.621-12.624)]$. Likewise, the children from families who living in rent house three times more likely under nutrition as compared with those who not renting house [AOR = $3.027(1.301-7.044)]$ and the children who did not feed appropriate complementary were three times more likely undernutrition as compared with those feed appropriate complementary feeding $[A O R=3.104(1.368-7.044)]$. The children those receiving vitamin A where less likely undernutrition as compared those who did not receive $[A O R=0.167(0.083-0.338)]$. The children held in growth monitoring were less likely develop under nutrition as compared with not followed by growth monitoring [AOR = $0.288(0.142-0.584)]$. Likewise, children who feeding breast were less likely develop under nutrition as compared with those who currently not feeding breast [AOR $=0.256(0.107-0.610)]$. Children who did not sick recently were less likely develop undernutrition as compared with those had diseases [AOR = $0.176(0.073-0.420)]$ (Table 6). 
Table 6

Factors associated with under nutrition among infants and young children age 6-23 months attending Minilik II Hospital, Ethiopia, 2021.

\begin{tabular}{|c|c|c|c|c|c|c|}
\hline & & Undernutritic & & Crude odd & AOR (at 95\% & P- \\
\hline & & yes & No & & & \\
\hline Working & Employed & $90(48.9 \%)$ & $94(51.1 \%)$ & $4.178(2.595-$ & $6.142(2.900-$ & 0.000 \\
\hline mother & housewife & $33(18.6 \%)$ & $44(81.4 \%)$ & & & ** \\
\hline $\begin{array}{l}\text { Educational } \\
\text { status of }\end{array}$ & $\begin{array}{l}\text { No } \\
\text { education }\end{array}$ & $104(50.5 \%)$ & $102(49.5 \%)$ & $\begin{array}{l}7.298(4.201- \\
12.679)\end{array}$ & $\begin{array}{l}5.752(2.621- \\
12.624)^{*}\end{array}$ & 0.000 \\
\hline & educated & 19(12.3\%) & 136(87.7\%) & & & \\
\hline Living in rent & yes & $96(43.4 \%)$ & $125(56.6 \%)$ & $3.214(1.955-$ & 3.027 & 0.010 \\
\hline & no & 27(19.3\%) & 113(80.7\%) & & $7.044)$ * & ** \\
\hline Appropriate & yes & $33(20.4 \%)$ & $129(79.6 \%)$ & $3.228(2.010-$ & $3.104(1.368-$ & ** \\
\hline 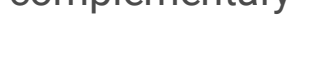 & No & $90(45.2 \%)$ & 109(54.8) & & & 0.007 \\
\hline Receiving & yes & $37(17.1 \%)$ & 179(82.9\%) & $0.142(0.087-$ & $0.167(0.083-$ & 0.000 \\
\hline & No & $86(59.3 \%)$ & $59(40.7 \%)$ & & & ** \\
\hline Growth & Yes & $35(17.4 \%)$ & 166(82.6\%) & $0.173(0.107-$ & $0.288(0.142-$ & 0.001 \\
\hline & No & $88(55 \%)$ & $72(45 \%)$ & & & ** \\
\hline Currently on & yes & $76(26 \%)$ & $216(74 \%)$ & $0.165(0.093-$ & $0.256(0.107-$ & 0.002 \\
\hline & No & $47(6.8 \%)$ & $22(31.9 \%)$ & & & ** \\
\hline Sick & yes & $53(72.6 \%)$ & $20(27.4 \%)$ & $0.121(0.068-$ & $0.176(0.073-$ & 0.000 \\
\hline & No & $70(24.3 \%)$ & $218(75.7 \%)$ & & & ** \\
\hline Key *Associated & riable after & djusted. & & & & \\
\hline$* * p$-value of ref & nce group & & & & & \\
\hline
\end{tabular}

\section{Discussion}

The study found $34.1 \%$ (at $95 \% \mathrm{Cl}(29.2 \%-39.2 \%)$ ) of young age children were undernutrition, while one hundred four (28.8\%) (at $95 \% \mathrm{Cl}(24.2 \%-33.8 \%)$ ) of them stunted, thirty-seven $10.2 \%$ (at $95 \% \mathrm{Cl}(7.3-$ $13.9 \%)$ ) were underweight and $4.7 \%$ (at $95 \%(\mathrm{Cl} 2.4-7.4 \%)$ of them were wasted. The finding of stunted were consistent with study conducted in Tanzania (31\%)(26), in Indonesia (28\%)(23) and Nigeria (24.6\%) (25). But less than finding of study conducted Pakistan (45\%)(22), study conducted in India (51.4\%)(23), study reported from Tigray region 56.6\% (27) and another study conducted in Ethiopia (39.8\%)(28) and 
higher than study conducted in East Ethiopia (22.9\%)(12). The variation of finding may be due to socio demographic, socio-economic and time point of study conducted.

This study indicated the magnitude of underweight was $10.2 \%(95 \% \mathrm{Cl}(7.3 \%-13.9 \%))$, it is lower than the study reported from Pakistan, the study reported from Tanzania (14\%)(26), Nigeria (33.3\%)(25) and study conducted in India (36\%)(23). Likewise, very far from study reported from Tigray (45.3\%)(27), Addis Ababa (54.1(9) and study reported from Somalia region (east Ethiopia) (19.5\%)(9). The variation is due to socioeconomic difference and due to methodological discrepancy.

Wasting is acute form of under nutrition by measuring weight with respect to length of the children, $4.7 \%$ (at 95\% (Cl 2.4-7.4\%)) of young age children were reported as wasted. The report was agreed with study conducted in Tanzania(26) and was very less when compared with study conducted in Nigeria(25) and Tigray region(27), while nearest to the study conducted and nearly half of study conducted in India(23). The variation may be due to geographical variation or economic status of the community.

The prevalence of undernutrition was high among male children (37.1\%) when compared with female (30.5\%). Similarly stunting (30.5\%) and wasting (14.2\%) also high among male when compared with female $26.8 \%, 5.5 \%$ respectively. This finding is relatively consistent with study conducted in Tigray region (29). In contrast, children 12-23 months were more under nourished and wasted while children 6-11 months were more underweight.

Working condition and educational status of the mothers were significantly associated with under nutrition. Employed mother were far from their child during working hours that had potential to reduce feeding practice of children and care. In this study children from employed mothers were six times more likely being undernutrition or half of children from employed mothers were under nutrition. This finding is consistent with study conducted in Ethiopian government hospitals(18).

Educational status was found to be associated factor of child undernutrition. in this study maternal illiteracy was increasing odd of children undernutrition. This finding was consistent by increasing odd with study conducted in Ethiopa (18) and Tanzania(25).

Appropriate complementary feeding is including, appropriate time, appropriate amount, appropriate frequency, appropriate type and safe food. Inappropriate complementary feeding was another factor that odd of under nutrition. In this study the children who did not feed appropriate complementary were three times more likely to being undernutrition. this finding is consistent with study conducted in Burkina Faso (26), Nigeria (25), Tanzania (27) and East Ethiopia Somali region (12).

Micronutrient supplementation another important predictor for undernutrition. in this study children received vitamin A supplement within past six months were less likely undernutrition. This finding was consistent with report of study conducted East Belesa District, northwest Ethiopia (29).

Breast feeding another important predictor of children undernutrition. in this study Currently on breast feeding was decreasing odd of undernutrition while not breast feeding was increasing odd by 3.9 times. 
This finding of study were agreed with study conducted in Tanzania which is breast feeding were increasing odd by 3.7(29) (30) and consistent with study conducted in East Ethiopia(Somalia region) (12). Another study conducted in Ethiopia also showed short duration of breast feeding increase odd of under nutrition(31).

Disease condition increase odd of under nutrition. In this study sick children were 5.6 times more likely being under nutrition while health children were less likely under nutrition. This finding was agreed with report of study conducted in Burkina Faso (34) and Granada, Nicaragua (35). In this report most prevalent disease were diarrhea, cough and fever as like as study conducted in Granada,Nicaragua. This finding indicated $77.8 \%$ of children infected with diarrheal disease and $71.4 \%$ of children infected with respiratory disease were under nutrition. This indicated how disease increase the risk of undernutrition. this finding was consistent with study conducted in Ethiopia (28), (29).

Living in rent house is found to be another predictor, this may be related with economic why because the report indicated $24.4 \%$ of household living in rent house were exhausted to buy food due to over payment for rent house. In this study the children from household living rent house were three times more likely to being undernutrition.

Growth monitoring an important program which used to monitoring the nutritional status of children from time to time. This variable is not addressed by many studies. In this study growth monitoring were found decreasing odd of children under nutrition and children who did not hold under the program were 3.4 times more likely being under nutrition.

\section{Conclusion And Recommendation 5.1 Conclusion}

The magnitude of undernutrition found to be high, particularly the magnitude of stunted was higher than previous findings. Working condition of mothers, educational status of mothers, living in rent house and disease condition were found to be increasing odd of undernutrition while Appropriate complementary feeding, receiving vitamin $A$, growth monitoring and Breast feeding were reducing odd of undernutrition.

\subsection{Recommendation}

Health education and promotion are important for mothers and caregiver to improving concept of nutritional status, young age feeding practice and food safety. Receiving vitamin, A supplements based on program and growth monitoring of children at health facilities is suggested. Appropriate complementary feeding after 6 months and optimum breast feeding until two-year age are recommended. Necessary strategy and program are needed to solve the problem raised with undernutrition. Further investigation is suggested by considering qualitative data and variables not considered by many studies like renting house and etc.

\section{Declarations}


Ethical clearance was taken from Addis Ababa public health research and emergency directorate after request letter obtained from Rift Valley University Abichu Compus. Permission letter was taken from Minilik II hospital administrative office. The informed consent was obtained with family of infants and children. The collected data was intended only for the purpose this study. No right or benefit taken away from non-response family because of they refuse to response.

\section{Consent for Publication}

'Not applicable'.

\section{Availability of Data and Materials}

The finding of this study is generated from the data

collected and analyzed based on stated methods and materials.

The original data supporting this finding are available from the

corresponding author on reasonable request.

\section{Competing Interests}

The authors declare that they have no competing interests.

\section{Authors' Contributions}

Lelisa Worku, Desta Assefie, participated in the design of the study, performed the data collection and the statistical analysis and served as the corresponding author of the manuscript. Dube jara give constructive advice, assist analysis and interpretation of the data. Addisu Tadesse supervised the study, ensured quality of the data All authors read and approved the manuscript.

\section{Authors' Information}

LW is Nutritionist, Nurse professional and chief medical laboratory technician at private sector, Lega Tafo, Oromia region, Ethiopia.

DA is nutritionist and Senior nurse professional at Menelik II hospital, Addis Ababa, Ethiopia.

DJ is PhD candidate and vice dean of postgraduate at Rift valley university, Addis Ababa, Ethiopia.

AT is senior nurse professional and TB focal person at Kimbibit Woreda Health office, Oromia region, Ethiopia.

\section{Acknowledgements}


Our gratitude goes to all data collectors, mothers/caregiver who give their time to response all important questions, Minilik hospiatal administrative and staff for their contribution.

\section{Abbreviations}

AOR Adjusted Odd Ratio

BMI Body Mass Index

HAZ Height for Age Z-score

IYCF Infant and Young Child Feeding

MUAC Middle Upper Arm Circumference

SPSS Statistical Package for Social Sciences

WAZ Weight for Age Z-score

WHO World Health Organization

WHZ Weight for Height Z-score

\section{References}

1. The Global Nutrition Report. The Burden of Malnutrition. 2018 Global Nutrition Report. 2018.

2. WHO. Fact Sheets: Malnutrition. Fact Sheets: Malnutrition. 2020.

3. Unicef/ WHO/The World Bank. Levels and Trends in Child malnutrition - Unicef WHO The World Bank Joint Child Malnutrition Estimates, key findings pf the 2019 edition. Unicef. 2019;

4. Keeley B, Chief E, Little C, Vrolijk K, Analyst D, Wauchope S, et al. Children, Food and Nutrition. UNICEF. 2019.

5. Endris N, Asefa H, Dube L. Prevalence of Malnutrition and Associated Factors among Children in Rural Ethiopia. Biomed Res Int. 2017;

6. Akombi BJ, Agho KE, Merom D, Renzaho AM, Hall JJ. Child malnutrition in sub-Saharan Africa: A meta-analysis of demographic and health surveys (2006-2016). PLoS One. 2017;

7. Amare ZY, Ahmed ME, Mehari AB. Determinants of Nutritional Status among Children Under five age in Ethiopia: A Further Analysis of the Ethiopian Demographic and Health Survey (EDHS) 2016 Data. bioRxiv. 2019.

8. Tekile AK, Woya AA, Basha GW. Prevalence of malnutrition and associated factors among under-five children in Ethiopia: Evidence from the 2016 Ethiopia Demographic and Health Survey. BMC Res Notes. 2019; 
9. Kore C, Ketema A. Assessment of Prevalence of Malnutrition among Children Age 6-59 Months at Woreda 06, Gulele Subcity, Addis Ababa, Ethiopia, 2017. J Nutr Disord Ther. 2018;

10. UNICEF. Malnutrition - UNICEF DATA. UNICEF, WHO and World Bank Group. 2017.

11. França TGD, Ishikawa LLW, Zorzella-Pezavento SFG, Chiuso-Minicucci F, Da Cunha MLRSM, Sartori A. Impact of malnutrition on immunity and infection. Journal of Venomous Animals and Toxins Including Tropical Diseases. 2019.

12. Fekadu Y, Mesfin A, Haile D, Stoecker BJ. Factors associated with nutritional status of infants and young children in Somali Region, Ethiopia: A cross- sectional study Global health. BMC Public Health. 2015;

13. Talukder A. Factors Associated with Malnutrition among Under-Five Children: Illustration using Bangladesh Demographic and Health Survey, 2014 Data. Children. 2017;

14. Development Initiatives Poverty Research Ltd. 2018 Global Nutrition Report. Global Nutrition Report. 2018.

15. Amaral TF, Matos LC, Tavares MM, Subtil A, Martins R, Nazaré M, et al. The economic impact of disease-related malnutrition at hospital admission. Clin Nutr. 2017;

16. Correia MITD, Waitzberg DL. The impact of malnutrition on morbidity, mortality, length of hospital stay and costs evaluated through a multivariate model analysis. Clin Nutr. 2013;

17. Kimiywe J, Chege P. Complementary feeding practices and nutritional status of children 6-23 months in Kitui County, Kenya. J Appl Biosci. 2015;

18. Gelana G, Dessalegn B, Alemu G. Assessment of Breast Feeding Practice and Risk Factors Associated with Severe Acute Malnutrition among Children Admitted to Addis Ababa Governmental Hospitals, Ethiopia, 2014: A Cross-Sectional Facility Based Study. Open Access J Sci Technol. 2017;

19. Bain LE, Awah PK, Geraldine N, Kindong NP, Sigal Y, Bernard N, et al. Malnutrition in Sub - Saharan Africa: Burden, causes and prospects. Pan African Medical Journal. 2013.

20. World Health Organization. Infant and young child feeding. WHO Fact sheet. WHO Fact sheet. 2020.

21. Egata G, Berhane Y, Worku A. Seasonal variation in the prevalence of acute undernutrition among children under five years of age in east rural Ethiopia: A longitudinal study. BMC Public Health. 2013;

22. Rayhan MI, Khan MSH. Factors causing malnutrition among under five children in Bangladesh. Pakistan J Nutr. 2016;

23. Ahmad A, Madanijah S, Dwiriani CM, Kolopaking R. Complementary feeding practices and nutritional status of children 6-23 months old: Formative study in Aceh, Indonesia. Nutr Res Pract. 2018;

24. Kumar D, Goel NK, Mittal PC, Misra P. Influence of infant-feeding practices on nutritional status of under-five children. Indian J Pediatr. 2016;

25. Udoh EE, Amodu OK. Complementary feeding practices among mothers and nutritional status of infants in Akpabuyo Area, Cross River State Nigeria. Springerplus. 2016;

26. Khamis AG, Mwanri AW, Ntwenya JE, Kreppel K. The influence of dietary diversity on the nutritional status of children between 6 and 23 months of age in Tanzania. BMC Pediatr. 2019; 
27. Alemayehu M, Tinsae F, Haileslassie K, Seid O, Gebregziabher G, Yebyo H. Undernutrition status and associated factors in under-5 children, in Tigray, Northern Ethiopia. Nutrition. 2015;

28. 28.

29. Fentahun W, Wubshet M, Tariku A. Undernutrition and associated factors among children aged 6-59 months in East Belesa District, northwest Ethiopia: A community based cross-sectional study. BMC Public Health. 2016;

30. Abubakar A, Uriyo J, Msuya SE, Swai M, Stray-Pedersen B. Prevalence and risk factors for poor nutritional status among children in the Kilimanjaro Region of Tanzania. Int J Environ Res Public Health. 2012;

31. Getahun Z, Urga K, Genebo T, Nigatu A. Review of the status of malnutrition and trends in Ethiopia. Ethiop J Heal Dev. 2015;

32. Tadesse A. Nutritional Status and Associated Factors Among Pastoralist Children Aged 6-23 Months in Benna Tsemay Woreda, South Omo Zone, Southern Ethiopia. Int J Nutr Food Sci. 2018;

33. Rahman A, Iqbal Z, Bunn J, Lovel H, Harrington R. Impact of maternal depression on infant nutritional status and illness: A cohort study. Arch Gen Psychiatry. 2014;

34. Paré BC, Dahourou DL, Kabore A, Sana A, Kinda R, Ouaro B, et al. Prevalence of wasting and associated factors among 6 to 23 months old children in the sahel region of Burkina Faso. Pan Afr Med J. 2019;

35. Sakisaka K, Wakai S, Kuroiwa C, Flores LC, Kai I, Mercedes Aragón M, et al. Nutritional status and associated factors in children aged 0-23 months in Granada, Nicaragua. Public Health. 2016;

36. Saaka M, Wemakor A, Abizari AR, Aryee P. How well do WHO complementary feeding indicators relate to nutritional status of children aged 6-23 months in rural Northern Ghana? BMC Public Health. 2015;

37. Sawadogo PS, Martin-Prével Y, Savy M, Kameli Y, Traissac P, Traoré AS, et al. An infant and child feeding index is associated with the nutritional status of 6- to 23-month-old children in rural Burkina Faso. J Nutr. 2016;

38. Kasaye HK, Bobo FT, Yilma MT, Woldie M. Poor nutrition for under-five children from poor households in Ethiopia: Evidence from 2016 Demographic and Health Survey. PLoS One. 2019;

39. Derso T, Tariku A, Biks GA, Wassie MM. Stunting, wasting and associated factors among children aged 6-24 months in Dabat health and demographic surveillance system site: A community based cross-sectional study in Ethiopia. BMC Pediatr. 2017;

40. WHO, UNICEF. Child growth standards and the identification of severe acute malnutrition in infants and children: A Joint Statement by the World Health Organization and the United Nations Children's Fund. WHO Press. 2019.

\section{Figures}




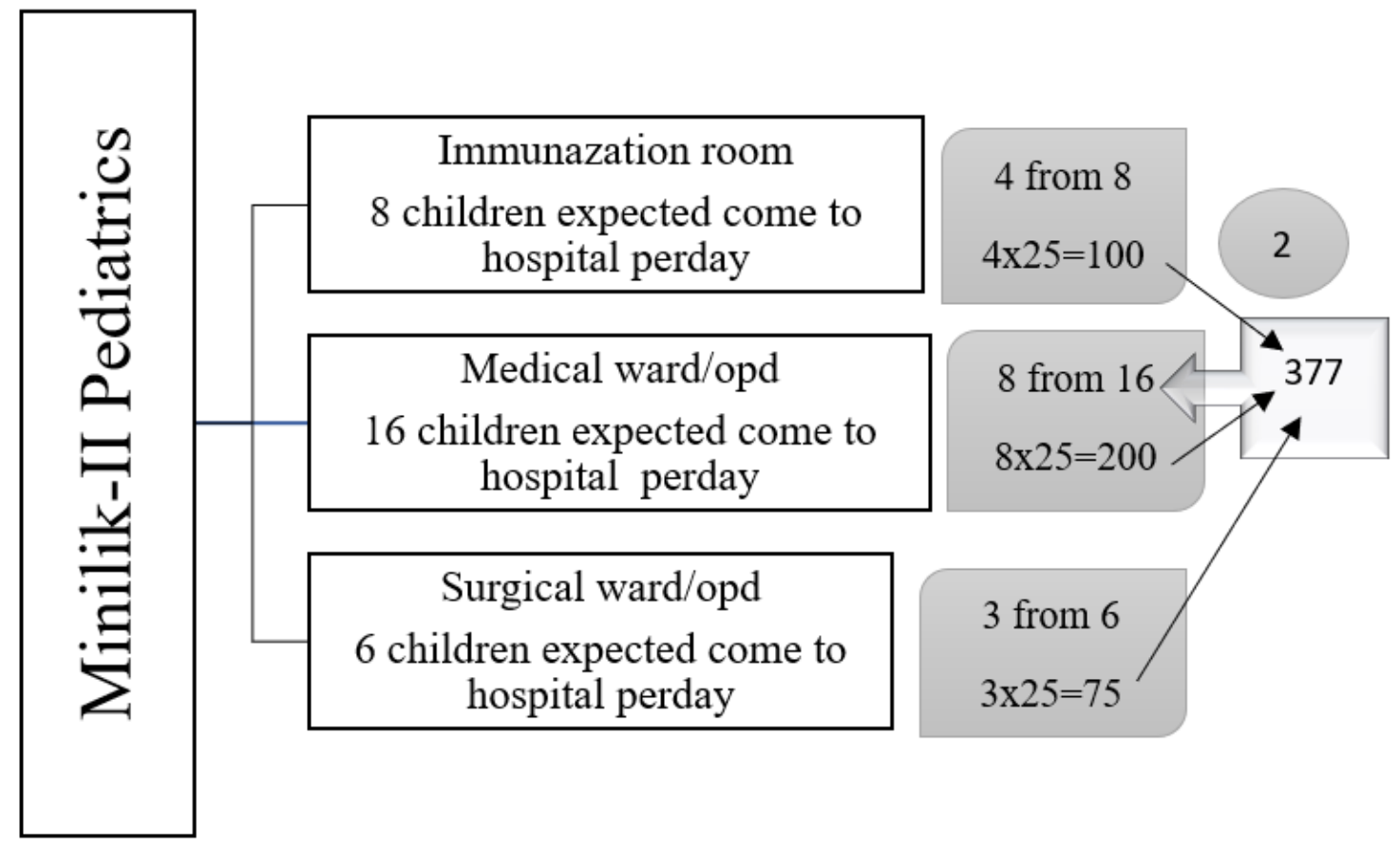

\section{Figure 1}

sampling method of infants and young age children 6-23 months at Minilik II hospital, Addis Ababa, Ethiopia, 2021

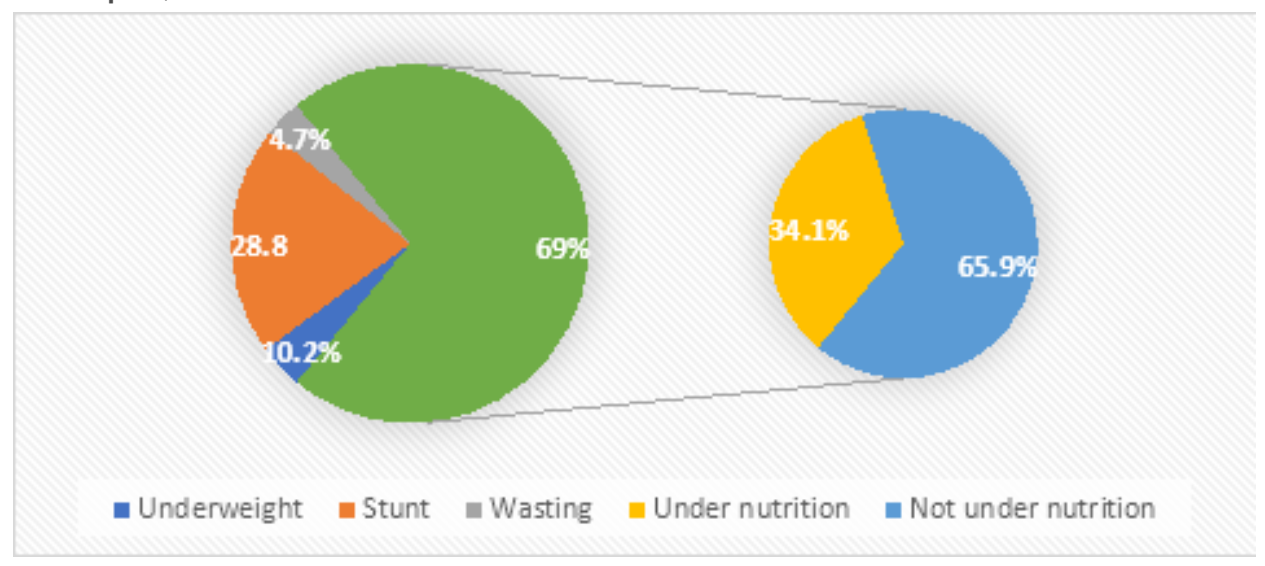

Figure 2

Magnitude of under nutrition among infants and young children age 6-23 months attending Minilik II Hospital, Ethiopia, 2021. 